\title{
Advances in Biochemical and Microbial Technologies
}

Lu C*

Department of Pediatrics, University of Louisville, USA

\section{Introduction}

Advancements in biochemical and microbial technologies help in designing new innovative drugs for many diseases. Journal of Microbial \& Biochemical Technology publishes articles related to current trends and latest developments in microbial and biochemical technologies. The current issue, i.e., volume no. 8 issue no. 5 has nine research articles, one short communication, and two review articles focusing on optimization of L-glutaminase production, bioactive compounds in barley, antibacterial activity of some plant extracts, aflatoxins in Maize, choline-amino acid based ionic liquids (AAIL), Zika virus, microbial fuel cell, improve growth and productivity of Maize, antifungal potential of silver nanoparticles, Epstein-Barr virus, environmental mycological load and chromatic biosensor.

Glutaminase is an amidohydrolase enzyme that converts glutamine to glutamate. This enzyme has wide applications in industries and is an important enzyme in biological systems. Ahmed et al. studied the potential of endophytes of marine invertebrates especially Aspergillus sp. ALAA-2000 in the production of L-glutaminase. Authors optimized the production process by changing the process parameters such as incubation temperature, time, $\mathrm{pH}$, etc., and using low-cost substrates for the enzyme production [1].

Many microbial compounds are known to increase the nutrient quality of the plant produce. Yousaf et al. in their research article analyzed the biochemical compounds present in Acetobacter aceti which can induce nutritional elements such as vitamins in barley seeds [2]. Authors isolated and analyzed thirteen chemical compounds of $A$ aceti. Their studies showed that among the 13 compounds five chemical compounds namely mevalonic acid, pyridoxic acid, quinolinic acid, $\alpha$-oxobutanoic acid, and p-aminobenzoate were significantly associated with increased quantities of phenols, phytosterols, and vitamins content in the barley seeds.

In the past decade the emergence of multidrug resistant (MDR) bacterial pathogens has significantly increased. Moreover, bacteria are capable of transmitting the drug resistance and acquiring resistance to new drugs. More than $60 \%$ of the populations in developing countries are still using traditional herbal medicines as a part of their primary healthcare. In the research article Agarwal et al. analyzed the antimicrobial potential of ethanolic extracts of Ageratum conyzoides, Camellia sinensis, Phyllanthus emblica and Mentha longifolia on multidrug resistant Staphylococcus aureus and Enterococcus faecalis. Authors found that ethanolic extracts of Mentha longifolia are potential against Enterococcus faecalis and Camellia sinensis against Staphylococcus aureus [3].

Maize is a staple food in many regions of the world and in some cultures it has central place in the diet, for example, in Mexican diet almost in every dish or cuisine, maize is used. Aflatoxins produced by some fungal species significantly affect the plant growth and its resistance power towards drought or any insects or pests. Rojas et al. in their study analyzed the role of maize germ in controlling the aflatoxins by the plant [4]. Their studies have shown that the linoleic acid present in the germ potentially inhibits aflatoxins B1 and G1. In another research article Amanullah et al. studied the efficacy of foliar fertilizers such as foliar zinc and phosphorus in increasing the productivity of maize under stressed conditions [5]. Their studies have shown that these foliar fertilizers significantly improved the growth and productivity of maize under moisture stressed conditions.

Salts having short-lived ion pairs and liquids below $100^{\circ} \mathrm{C}$ are termed as ionic liquids (IL). These ionic liquids have wide applications in pharmaceuticals, cellulose processing, nuclear fuel reprocessing, solar thermal energy, waste recycling, carbon capture, nanotechnology, etc. Choline-amino acid based ionic liquids can be synthesized from choline and amino acids present in biological systems. In the research article, Yazdani et al. described the process of synthesizing biocompatible and biodegradable AAIL and evaluated its biocompatible and biodegradable properties using various strains of microorganisms [6].

Zika virus is an icosahedrally symmetrical, enveloped, single stranded, positive sense RNA genome virus and is closely related to Spondweni virus. Wilde et al. in their research article investigated physical and chemical inactivation approaches of Zika virus [7]. Their studies concluded that Zika virus is susceptible to commonly used disinfectants like other flaviviruses.

Azo dyes are synthetic dyes that are used in various industries like fabrics. More than $10 \%$ of the dye will be wasted and sent into environment as runoff. Shaikh et al. in their research article determined the efficiency of microbial fuel cell (MFC) in decolorizing this dye polluted water. Authors concluded that Bacillus circulans an electrogenic bacterium has the potential to be used in MFC technology and this technology is far better than the traditional anaerobic technology [8].

In the recent years biosynthesis of nanoparticles has been the area of research interest in nanotechnology. Khan et al. produced silver nanoparticles by using fungus namely Penicillium fellutanum [9]. These nanoparticles were found to be having antifungal properties against Candida glabrata, Candida albicans and Candida tropicalis.

Tsai et al. in his short communication described the importance of chromatic detection of antigens in clinical applications as they can be read without any software or instrument. Authors presented a range tunable chromatic biosensor that can detect antigen and demonstrated its efficacy by using human serum albumin [10].

More than $90 \%$ of the world population is asymptomatically infected with Epstein-Bar virus or its subtypes. In the review article Caetano et al. briefly described about various physiological changes in kidney and salivary glands that can help in the diagnosis of EpsteinBarr virus [11].

*Corresponding author: Lu C, Department of Pediatrics, University of Louisville USA, Tel: 852-2214; E-mail: L0cai001@louisville.edu

Received January 09, 2017; Accepted January 10, 2017; Published January 16 2017

Citation: Lu C (2017) Advances in Biochemical and Microbial Technologies. J Microb Biochem Technol 8: e126. doi: 10.4172/1948-5948.1000e126

Copyright: () 2017 Lu C. This is an open-access article distributed under the terms of the Creative Commons Attribution License, which permits unrestricted use, distribution, and reproduction in any medium, provided the original author and source are credited. 
Masaphy et al. in their review article briefly discussed the importance of monitoring mycological load in the environment and its effect on public health. Authors described all the available fungal identification and monitoring methods that can provide quantitative or qualitative information of fungal presence or the presence of their secondary metabolites/toxins [12].

\section{References}

1. Ahmed MMA, Taha TM, Abo-Dahab NF, Hassan FSM (2016) Process optimization of L-glutaminase production; a tumour inhibitor from marine endophytic isolate Aspergillus sp. ALAA-2000. J Microb Biochem Technol 8: 382- 389.

2. Yousaf A, Ashraf Y, Yasin NA, Ibrahim A, Ahmad A, et al. (2016) Analysis of microbial biochemical inducting nutritional contents in barley. J Microb Biochem Technol 8: 395-403.

3. Agarwal P, Agarwal N, Gupta R, Gupta M, Sharma B (2016) Antibacterial activity of plants extracts against methicillin-resistant Staphylococcus aureus and vancomycin-resistant Enterococcus faecalis. J Microb Biochem Technol 8: 404-407.

4. Vega-Rojas LJ, Carvajal-Moreno M, Rojas-Molina I, Rojo-Callejas F, RuizVelasco S, et al. (2016) The effect of maize germ on the presence of aflatoxins in corn flours treated with a thermo-alkaline process. J Microb Biochem Technol 8: $408-414$.
5. Amanullah, Saleem A, lqbal A, Fahad S (2016) Foliar phosphorus and zinc application improve growth and productivity of maize (Zea mays L.) under moisture stress conditions in semi-arid climates. J Microb Biochem Technol 8: 433-439.

6. Yazdani A, Sivapragasam M, Levêque JM, Moniruzzaman M (2016) Microbial biocompatibility and biodegradability of choline-amino acid based ionic liquids. J Microb Biochem Technol 8: 415-421.

7. Wilde C, Chen Z, Kapes T, Chiossone C, Lukula S, et al.(2016) Inactivation and disinfection of zika virus on a nonporous surface. J Microb Biochem Technol 8: $422-427$.

8. Shaikh J, Patil NP, Shinde V, Gaikwad VB (2016) Simultaneous decolorization of methyl red and generation of electricity in microbial fuel cell by Bacillus circulans NPP1. J Microb Biochem Technol 8: 428-432.

9. Khan NT, Jameel N (2016) Antifungal activity of silver nanoparticles produced from fungus, Penicillium fellutanum at different $\mathrm{pH}$. J Microb Biochem Techno 8: $440-443$.

10. Tsai $\mathrm{CH}$, Hong YJ, Huang JH, Chang P, Yew TR (2016) A readable chromatic biosensor with a tunable detection threshold. J Microb Biochem Technol 8: 390394

11. Caetano LP, Costa KCT, Moraes ABA, Alves-Balvedi RP (2016) Physiological changes in salivary gland and kidney that help the diagnosis caused of EpsteinBarr virus: A brief review. J Microb Biochem Technol 8: 444-448.

12. Masaphy S, Ezr R (2016) Targeted inspection of environmental mycological load for mitigation of indoor mold toward improved public health. $\mathrm{J}$ Microb Biochem Technol 8: 449-458. 